\title{
KONSTRUKSI TEMPAT-TEMPAT DI ASIA DALAM MAJALAH MASKAPAI PENERBANGAN Analisis Isi Mediasi Ruang dan Pengalaman Keruangan di Majalah Maskapai Penerbangan Airasia Travel 3 Sixty
}

\author{
Raisa Hashina Rosalini \\ Alumni Komunikasi Universitas Islam Indonesia \\ hashinaraisa@gmail.com
}

\begin{abstract}
Abstrak
Majalah maskapai penerbangan memediasi ruang atau tempat hingga pengalaman pariwisata. Mediasi tersebut kemudian mengkonstruk sebuah ruang atau tempat. Penelitian ini bertujuan untuk menganalisis konstruksi tempat serta model pengalaman wisata di Asia dalam rubrik Travel Log, majalah maskapai penerbangan Travel 3Sixty. Data di analisis dengan menggunakan metode analisis konten. Hasil penelitian menunjukkan Asia dikonstruk sebagai tempat budaya yang ramah yang dapat memberikan pengalaman keaslian. Dihasilkan juga bahwa majalah maskapai penerbangan menjadi media baru yang dapat mengkonstruk elemen lokal menjadi elemen global.
\end{abstract}

Keyword : Traveling, media baru, mediasi tempat dan pariwisata, konstruksi akan tempat, lokal-global.

\begin{abstract}
In-flight magazine mediated space or place to experience of tourism. Then the mediation was contruct of place or space. This study aims to analyze construction of place and models of tourism experience in Asia in the Travel Log rubric, Travel 3Sixty in-flight magazine. The data was analyzed with content analysis method. The result shows that Asia is constructed as a friendly culture place that can provide experience of authentic experience. The research also show that in-flight magazine is a new media which can construct local element into a global element.
\end{abstract}

Keyword : in-flight magazine, mediating place, communication geography, content analysis, construction of Asia. 


\section{Pendahuluan}

Dahulu, traveler atau orang yang melakukan perjalanan memiliki tujuan untuk mendapatkan sesuatu yang baru, terutama pengalaman religius. Dengan adanya perkembangan zaman, perjalanan bukan hanya menjadi perjalanan religius, tapi juga pengalaman lainnya. Travelling kemudian berkembang menjadi tourism. Menurut Adler (dalam Urry (ed) 2005: 4), perkembangan ini terjadi karena adanya catatan-catatan selama perjalanan. Dengan adanya catatan-catatan selama perjalanan, seseorang bisa menggunakannya sebagai acuan dalam perjalanan selanjutnya.

Menurut Thompson (2016: 58), Travel Writing atau catatan perjalanan pada umumnya berupa tulisan non-fiksi walaupun terkadang ada pula yang bersifat fiksi. Phillips (2014: 50) mengatakan bahwa travel writing merupakan istilah modern yang berasal dari kepustakaan perjalanan dalam tulisan cabang sastra yang telah dikenal. Sementara Lisle (2006: 142), berpendapat bahwa travel writing merupakan bagian utama imajinasi geografis yang baru, yang menghubungkan antarruang dengan karakteristik yang baru. Jadi, dapat disimpulkan bahwa travel writing merupakan tulisan non-fiksi atau fiksi yang menjadi bagian utama imajinasi geografis yang menghubungkan antarruang dengan karakteristik yang baru.

Saat ini, catatan perjalanan menjadi lebih beragam karena pesatnya perkembangan teknologi komunikasi. Bentuk kontemporer catatan perjalanan, misalnya, majalah, promosi, iklan, dan lain sebagainya. Daye (2005: 14) mengatakan bahwa sebelum berwisata seseorang akan mencari dan mendeskripsikan daerah wisatanya sesuai dengan cerita dari mulut ke mulut (word of mouth) iklan, promosi, atau pengalaman dari dirinya sendiri. Komunikasi menjadikan bertambahnya ketertarikan wisatawan terhadap objek wisata. Selain itu, komunikasi wisata atau mediasi wisata pada akhirnya mempengaruhi juga bagaimana masyarakat memandang destinasi wisata. Dengan kata lain, mediasi pariwisata tidak hanya mengubah sebuah 'lokasi geografis' menjadi 'destinasi' dalam level bahasa, melainkan juga membangun perilaku terhadap ruang destinasi tersebut sehingga menjadi sebuah ruang yang 'baru'.

Konsep ini dikenal sebagai tourist gaze yang diperkenalkan oleh John Urry. Tourist gaze merupakan pandangan wisatawan terhadap sebuah objek wisata yang dinamis karena adanya media/mediasi yang tidak hanya merepresentasikan, tapi juga mengkonstruk objek wisata (Urry, 2005: 11).

Salah satu efek konstruksi ruang wisata adalah globalisasi destinasi wisata. Globalisasi ini terlihat pada cara media menyusun sebuah tempat menjadi objek konsumsi global dengan menampilkan nilai-nilai global. Saat ini, banyak media menampilkan konten-konten lokal yang disajikan menjadi konsumsi global, yang kemudian disebut dengan konsep Lokalglobal.

Mike Featherstone (1993: 170) mengatakan bahwa modernisasi membuat objek yang tadinya bergerak dari asumsiasumsi non-barat menjadi lebih modern dengan mengadopsi dan menduplikasi nilai-nilai barat. Hal ini menghasilkan aspek global dalam sebuah objek, termasuk juga pada objek pariwisata.

Penelitian Marcella Daye (2005: 14-26) memperlihatkan bagaimana mediasi dalam pariwisata turut menyusun 
gambaran tentang Karibia, yang telah menjadi objek wisata global. Daye menyimpulkan bahwa Karibia dikonstruksikan menjadi tempat yang menyajikan "sun, sand, and salt" sehingga menghasilkan stereotip tentang pengalaman wisata. Gagasan Urry mengenai tourist gaze kemudian ditekankan kembali oleh Daye. Daye mengatakan bahwa perampasan tempat oleh industri menghasilkan perilaku konsumtif masyarakat kapitalis.

Salah satu media yang berperan dalam globalisasi ruang adalah majalah maskapai penerbangan. Majalah maskapai penerbangan sering kali menampilkan konten-konten lokal yang disajikan secara lebih modern. Thurlow dan Jaworski (2003: 580) mengatakan bahwa majalah maskapai penerbangan dapat menjadi media globalisasi dengan cara menampilkan aspek-aspek global.

Stefania Maria Maci (2012: 196218) membahas mengenai bagaimana globalitas ditampilkan dalam majalah maskapai penerbangan serta bagaimana menerapkan sikap global dalam budaya lokal yang dibawakan. Maci menyimpulkan bahwa majalah maskapai penerbangan menampilkan karakteristik lay-out global, misalnya, stereotip ruang yang menyediakan berbagai kemudahan dan keindahan.

Di Indonesia, penelitian mengenai konstruksi ruang dalam majalah maskapai penerbangan dilakukan oleh Dhona (2018). Dengan analisis wacana multimodal, Dhona memperlihatkan rangkaian narasi dan gambar serta proses produksi majalah maskapai penerbangan Colours yang ditangani oleh perusahaan global dengan cara-cara global, menampilkan Indonesia sebagai ruang global. Majalah maskapai penerbangan, menurut Dhona, adalah symbolic distancing, sebuah proses pen-jarak-an simbolik dari globalisasi itu sendiri.
Saat ini, Asia menjadi objek pariwisata yang banyak dikunjungi wisatawan. Asia memiliki banyak keistimewaannya tersendiri sebagai objek wisata, mulai dari beragam ras dan budaya, sejarah, kuliner, hingga flora dan fauna. Eratnya hubungan Asia dan pariwisata menjadikan Asia sebagai objek dari tourist gaze. Ini berarti bahwa wisatawan melihat Asia dipengaruhi oleh komunikasi/mediasi pariwisata.

Majalah maskapai penerbangan yang populer "memediasi" Asia adalah majalah Travel 3Sixty dari maskapai penerbangan AirAsia. Hal ini terkait erat dengan bagaimana ekspansi AirAsia menjadi maskapai penerbangan terkemuka di Asia. Masalahnya belum ada yang meneliti bagaimana efek mediasi Asia melalui majalah maskapai penerbangan AirAsia ini.

Penelitian ini tidak hanya terfokus pada mediasi ruang, tapi juga bagaimana mediasi pengalaman atas ruang yang termediatisasi. Majalah maskapai penerbangan tidak hanya memperkenalkan ruang, tetapi juga memperkenalkan bagaimana cara menikmati/mengalami ruang? Berangkat dari titik pijak ini, penelitian ini hendak menjawab tiga pertanyaan penting, yakni (1) bagaimana konstruksi tempat-tempat di Asia dalam rubrik Travel Log majalah Travel 3Sixty?; (2) bagaimana model pengalaman wisatawan dalam rubrik Travel Log majalah Travel 3Sixty?; (3) erta bagaimana aspek globalisasi yang diterapkan dalam rubrik Travel Log majalah Travel 3Sixty.

\section{Metode}

Penelitian ini menggunakan analisis isi kuantitatif. Analisis isi adalah sebuah alat yang digunakan untuk menganalisa dan menyimpulkan konsep 
atau kata dalam sebuah teks (Adiputra, 2008:103).

Unit analisis dalam penelitian ini adalah artikel rubrik Travel Log dalam majalah maskapai penerbangan Airasia Travel 3Sixty dengan periode 2015 hingga 2017 dengan jumlah total 36 majalah. Pemilihan majalah maskapai penerbangan sebagai unit analisis karena majalah maskapai penerbangan ini banyak menampilkan destinasi pariwiata terutama di Asia yang menjadikan fokus ruang dalam penelitian ini.

Penelitian ini dilakukan dengan beberapa tahapan. Pertama pengkategorian teks atau yang biasa disebut dengan definisi operasional. Dalam penelitian ini, konsep dari konteks artikel yang diteliti menggunakan tipologi pengalaman turis dan kategori tema dalam artikel. Analisis data didahului dengan pelatihan kepada dua koder mengenai setiap model tipologi dan kategori tema. Tahap selanjutnya, yakni pengkodean oleh koder. Tahap terakhir yakni lembar koding dianalisis serta membandingkan dua jawaban dari setiap koder untuk melihat perbedaan atau kesamaan pada jawabannya.

Dalam analisis isi diperlukan alat pengukur untuk menilai sebuah teks serta untuk membuktikan kesepakatan antara pelaku koding. Dalam penelitian ini, digunakan rumus Holsti, yakni sebagai berikut.

$$
\mathrm{CR}=\frac{2 M}{\mathrm{~N} 1+\mathrm{N} 2}
$$

$\mathrm{CR}=$ Koefisiensi reliabilitas

$\mathrm{M} \quad$ = Jumlah koding yang disepakati

$\mathrm{N} \quad=$ Jumlah data yang dikoding oleh dua koder
Holsti menganggap data analisis dianggap cukup reliabel jika kesepakatan antara dua koder mencapai 0.7.

$M=1104$
$N 1=1332$
N2 $=1332$

$$
\mathrm{CR}=\frac{2(1104)}{2664}=0.82
$$

Hasil uji reliabilitas mencapai 0.82 . Dengan demikian, kedua uji reliabilitas membuktikan bahwa kesepakatan antara dua koder adalah tinggi.

Analisis isi dilakukan dengan menggunakan kategori representasi ruang atau destinasi menurut Robert S. Dilley serta kategori pengalaman wisatawan menurut Eric Cohen. Dilley (1986:59-65) mengelompokkan tema dalam artikel berdasarkan ilustrasi yang terdapat dalam gambar dan teks dalam artikel. Terdapat empat kategori representasi ruang, yakni sebagai berikut.

a) pemandangan yang merujuk pada ilustrasi sebuah pemandangan seperti alam, pedesaan, perkotaan, dan sebagainya;

b) budaya merujuk pada ilustrasi mengenai sejarah, kesenian, kehidupan masyarakat sekitar dan sebagainya;

c) rekreasi merujuk pada sebuah tempat atau destinasi wisata yang memberikan suasana menarik untuk berlibur seperti scubadiving hingga permainan masyarakat lokal; dan

d) servis yang merujuk pada layanan yang terdapat pada daerah tertentu seperti pasar atau toko-toko lokal.

Konsep pengalaman wisata diambil dari Eric Cohen (1979: 179-199). Cohen mengatakan terdapat lima kategori pengalaman wisatawan, yakni sebagai berikut. 
a. rekreasional, wisatawan melakukan perjalanan ke tempat-tempat budaya sebagai upaya menghibur diri untuk mendapatkan pengalaman liburan dan relaksasi;

b. diversional, hampir sama dengan kategori rekreasional dalam kategori ini wisatawan melakukan perjalanan dengan tujuan untuk menghibur diri dan relaksasi namun tidak mementingkan keaslian (authentisitas) hanya saja menginginkan sesuatu yang berbeda dari yang biasa dijalani;

c. eksperiental, wisatawan melakukan perjalanan ketempat-tempat yang memiliki autentisitas untuk memenuhi kebutuhannya (real needs). Wisatawan melakukan perjalanan untuk mendapatkan pengalaman tradisional sebagai usaha melarikan diri dari kehidupan modern;

d. eksperimental, wisatawan melakukan perjalanan dengan tujuan mencari sesuatu yang berbeda dari yang biasa dijalani. Wisatawan ini mencari dan menikmati keaslian lokal dengan cara berbagi budaya dengan masyarakat lokal namun tidak berkomitmen (tinggal) dengan sebuah budaya;

eksistensial, hampir sama dengan kategori eksperimental, pada kategori ini wisatawan secara sukarela dan bersedia tinggal bersama penduduk lokal sebagai usaha untuk memenuhi kebutuhannya. Kategori ini menekankan bahwa wisatawan melakukan perjalanan dengan tujuan untuk mendapatkan dari sesuatu yang tidak berarti (meaningless) menjadi sesuatu yang berarti.

\section{Hasil dan Pembahasan}

Dalam rubrik Travel Log, kebanyakan konten dan destinasi yang dimunculkan merupakan destinasi yang berasa di kawasan Asia seperti Filipina, Malaysia, Indonesia dan lainnya, tapi tidak menutup kemungkinan memunculkan negara di benua lain seperti Hawaii dan Australia.

Dalam berwisata, tentunya, seseorang pergi ketempat atau destinasi yang menarik dan berbeda dari tempat yang pernah dikunjungi. Terkadang, daerah yang dikunjungi pun bukan daerah yang dirasa memiliki destinasi wisata yang cukup banyak atau tempat yang bukan sebuah destinasi wisata.

Dalam salah satu artikel di rubrik Travel Log bulan Juni 2017, misalnya, terdapat wisatawan yang mengunjungi Iran bukan hanya menjadi destinasi hiburan, tapi juga menjadi destinasi penyejuk hatinya.

Rubrik Travel Log dianalisis dengan menggunakan kategorisasi tempat atau destinasi wisata oleh Robert S. Dilley (1986: 59-65), sementara penggambaran pengalaman atas ruang didasarkan pada konstruksi pengalaman atas tempat menurut Eric Cohen (1979: 179-199).

Analisis mengenai kategorisasi tempat atau destinasi menghasilkan kebanyakan tempat yang dikunjungi wisatawan adalah tempat atau destinasi budaya yang disebutkan sebanyak 177 kali. Destinasi budaya banyak diilustrasikan dengan penampilan seni dan arsitektur sebuah destinasi. Selanjutnya, pemandangan yang disebutkan sebanyak 175 kali. Pemandangan digambarkan bukan hanya pemandangan yang bertemakan alam, tapi juga pemandangan urban, rural, dan sebagainya. Destinasi ketiga yang banyak dipilih wisatawan, yakni destinasi yang memiliki layanan yang disebutkan sebanyak 168 kali. Tempat-tempat layanan yang banyak dikunjungi wisatawan antara lain seperti toko-toko atau pasar tradisional hingga layanan pada tempat penginapan. Kategori terakhir, yakni tempat rekreasi yang paling 
sedikit dikunjungi, yakni sebanyak 101 kali, dimana kategori ini merujuk pada sebuah tempat yang sengaja diciptakan atau disediakan oleh masyarakat sehingga menjadi daya tarik wisata.

Analisis mengenai konstruksi pengalaman menunjukkan bahwa model rekreasional menjadi model pengalaman wisatawan yang dominan yang muncul sebanyak 57 kali. Model kedua terbanyak, yakni model diversional yang muncul sebanyak 52 kali. Pada urutan ketiga, model eksperimental muncul dengan disebutkan sebanyak 47 kali.

Tabel 1 Penggambaran Tempat Wisata Asia

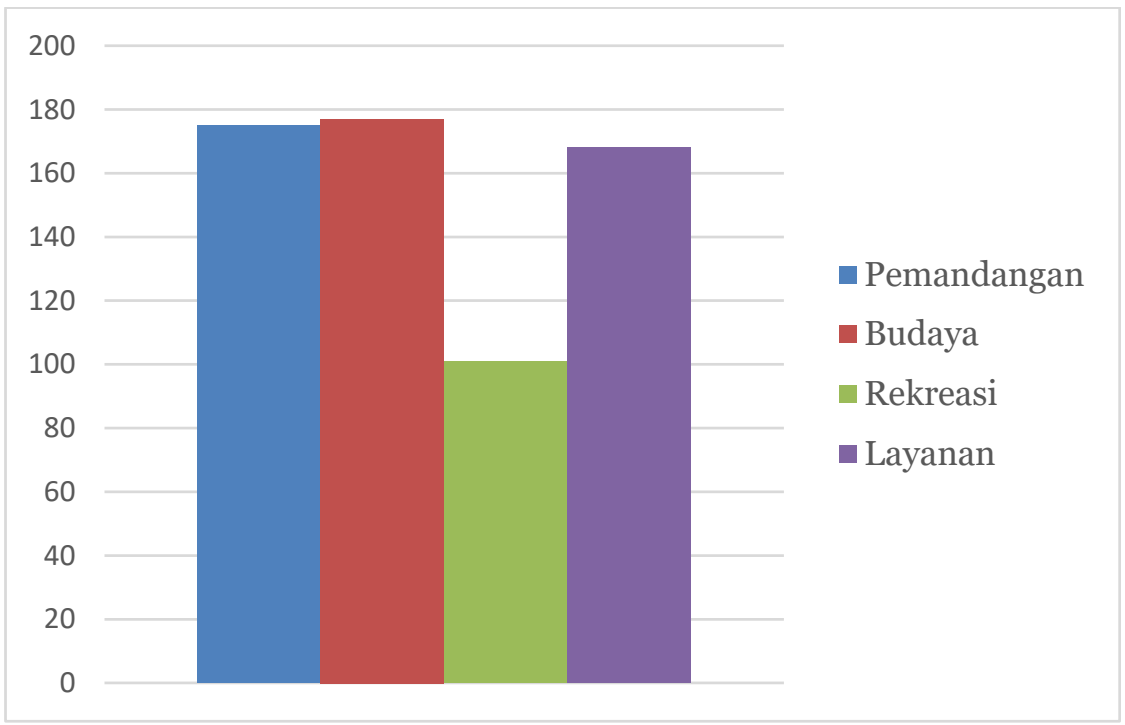

Keempat terdapat model eksperimental yang muncul sebanyak 17 kali. Serta model eksistensial muncul sebanyak 8 kali yang menjadikan model ini paling sedikit dilakukan oleh wisatawan.

Dalam mengalami sebuah tempat, tentu saja, wisatawan tidak mengalami satu model saja, tetapi juga bisa mengalami beberapa model. Asia sendiri menjadi tempat yang dapat memberikan beberapa model pengalaman. Dari satu ruang wisatawan, bisa mengalami beberapa model yang tertunya sesuai dengan ekpektasinya maupun diluar ekspektasinya. Dalam penelitian ini, juga mencari pengalaman wisatawan yang memiliki beberapa model dalam mengalami sebuah ruang. 
Tabel 2 Pengalaman di Tempat Wisata

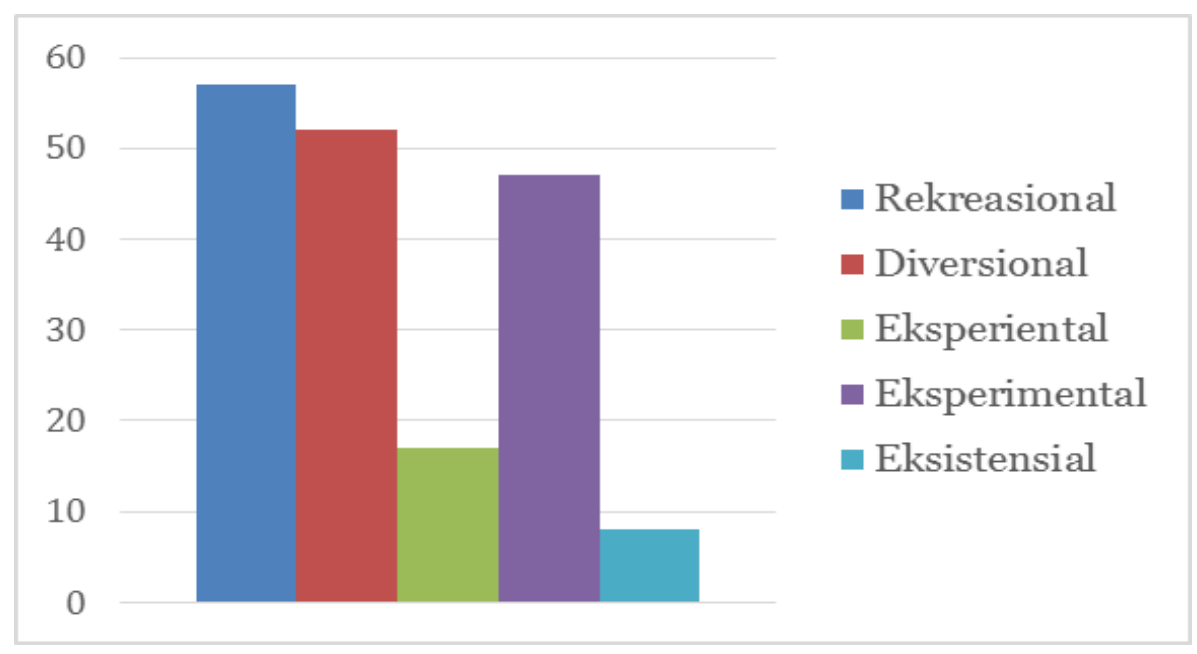

Dari data yang telah dianalisis, wisatawan mengalami beberapa model pengalaman dari satu ruang. Hal ini terlihat dari model rekreasional dan diversional disebutkan sebanyak sembilan kali; model rekreasional, diversional, dan eksperiental disebutkan sebanyak lima kali; model rekreasional, diversional dan eksperimental disebutkan sebanyak dua kali; rekreasional dan eksperimental disebutkan sebanyak delapan kali; model diversional dan eksperimental sebanyak empat kali; serta lain-lain (rubrik yang hanya memiliki satu model pengalaman) sebanyak delapan kali.

\section{Otensitas Asia: Asia Sebagai Tempat Budaya yang Ramah}

Dalam penggambaran sebuah tempat atau ruang, media memiliki peran utama dimana pada saat ini semua orang mencari informasi dengan menggunakan media yang kemudian terdapat mediasi dalam proses konstruksi terhadap ruang. Dalam proses mediasi, sebuah ruang dikonstruksi agar sesuai dengan apa yang di inginkan pembacanya.

Pariwisata yang saat ini menjadi trend dalam menghabiskan waktu luang seseorang menjadi salah satu ruang yang dikonstruksikan oleh media. Misalnya, untuk mendapatkan pengalaman liburan musim panas, wisatawan bisa mencari tempat yang lebih hangat seperti Asia tenggara, atau apabila ingin mendapatkan pengalaman religius wisatawan dapat mengunjungi tempat-tempat seperti Mekah bagi Muslim atau Thailand untuk wisatawan Hindu dan Budha.

Dalam model rekreasional yang menjadi model dominan dalam penelitian ini, digambarkan bahwa wisatawan banyak berkunjung ke tempat-tempat dengan tema alam, budaya, dan pemandangan. Model pengalaman rekreasional sejajar dengan penggambaran tempat wisata terutama di Asia yang sebagian besar dikonstruksikan sebagai ruang sebagai tempat budaya dan pemandangan.

Destinasi dengan tema budaya banyak dikunjungi wisatawan. Hal ini sesuai dengan apa yang dikatakan oleh Mckercher dan Du Cros (2012: 1) bahwa wisatawan ingin mencari keaslian (authentic) atas pengalaman yang lebih dalam dibanding dengan pengalaman wisata yang lainnya dengan tujuan untuk mengedukasi. 
Untuk menampilkan Asia yang otentik, tempat-tempat religi dikonstruksikan menjadi destinasi. Dalam beberapa artikel, wisatawan mengunjungi beberapa tempat religi bukan untuk ibadah.

$$
\text { Jika majalah maskapai }
$$
penerbangan adalah sebuah mediasi pariwisata dimana ia merupakan perwujudan dari Tourist Gaze, maka penelitian ini mendukung gagasan Urry (2005: 12-13) bahwa tourist gaze akhirnya mengubah ruang dan masyarakat menjadi objek wisata. Dengan adanya mediasi pariwisata, pandangan turis terhadap ruang menjadi berubah terlebih ketika berkembang menjadi pariwisata global.

Otensitas Asia sebagai tempat yang ramah juga ditunjukkan dengan penggambaran penduduk lokal Asia. Asia dikonstruksikan memiliki warga lokal yang ramah. Konstruksi keramahan penduduk lokal sebenarnya masih berkaitan dengan konsep budaya, dimana keramahan penduduk menjadi pendamping budaya dalam interaksi sosial masyarakat lokal dengan wisatawan.

Penggambaran keramahan lokal terlihat dalam salah satu artikel berikut ini.

... This one, with friendly local people and hospitable culture, ws my best pick." (Majalah maskapai penerbangan Travel 3Sixty rubrik travel log edisi April 2016: 112)

\section{Asia sebagai tempat pengalaman keaslian (authentic)}

Ruang atau destinasi budaya menjadi destinasi yang sering dikunjungi. Disamping mengenai sejarah dan bangunannya sering kali ruang budaya memiliki daya tarik lokal lainnya seperti atraksi budaya, kampung budaya, pengalaman sosial budaya hingga letak dari objek budaya tersebut. Bangunan ruang yang demikian disesuaikan dengan model pengalaman wisata eksperiental, eksperimental dan eksistensial, dimana sebagian besar tujuannya, yakni untuk mencari sesuatu yang berbeda dari apa yang biasa dijalaninya. Misalnya, mengunjungi sebuah perdesaan dan mengikuti secara langsung aktivitas masyarakat lokal akan menghasilkan pengalaman sosial yang berbeda dari yang biasa dijalani. Artinya, konstruksi pengalaman yang demikian memposisikan Asia sebagai tempat yang baru, berbeda, dan menjanjikan keaslian (authentic).

Temuan penelitian ini juga
menunjukkan bahwa destinasi
pemandangan menjadi daya tarik yang
hampir sama besarnya dengan destinasi
budaya. Ruang pemandangan ini
kemudian dikonstruksikan sebagai
tempat-tempat yang memberikan rasa
relaksasi, menyenangkan, dan
menenangkan sehingga dapat dijadikan
sebagai ruang baru untuk istirahat dari
kehidupannya. Hal ini menjadi daya tarik
positif terhadap wisatawan dengan model
rekreasional dan diversional yang memiliki
tujuan untuk menghibur diri.

Asia sendiri dapat dikatakan tempat yang murah, bukan hanya perekonomiannya, tapi juga murah dalam memberikan kesempatan banyak pengalaman dari satu ruang.

Dalam berwisata, seseorang dapat mengalami berbagai macam model pengalaman dari satu ruang destinasi. Maksudnya, walaupun seseorang memiliki satu tujuan wisata untuk relaksasi dan menghibur diri, tapi ia juga dapat memiliki pengalaman wisata lainnya percampuran dari beberapa model pengalaman pariwisata. Sebagai contoh, seseorang mengunjungi tempat-tempat sejarah, disamping menghasilkan pengalaman edukasi, ia juga akan mendapatkan pengalaman relaksasi dan hiburan dari mengujungi ruang tersebut. 


\section{Genre majalah maskapai penerbangan sebagai instrumen global}

Majalah maskapai penerbangan
adalah mediasi pariwisata yang mengkontestasikan konsep lokal dan global. Genre majalah maskapai penerbangan sebagai instrumen global dikemukakan oleh Thurlow dan Jaworski (2003: 581) yang mengatakan bahwa genre majalah maskapai penerbangan sebagai instrumen global membentuk tatapan turis terhadap sebuah ruang menjadi global. Majalah maskapai penerbangan menjadi instrumen global dengan cara menampilkan aspek-aspek global dalam majalahnya, bukan hanya informasinya saja, tapi juga tampilan majalahnya itu sendiri.

Helen Ye dan Iis P. Tussyadiah (2011: 135-136) mengatakan bahwa konsep lokal digambarkan dengan elemen bawah (low-level elements/object), dan konsep global digambarkan dengan elemen yang lebih tinggi (higher-level semantic). Ini bisa dilihat dalam salah satu artikel travel log yang menceritakan wisatawan menggunakan rumah penduduk lokal sebagai tempat istirahatnya. Dalam hal ini, rumah penduduk merupakan objek lokal yang kemudian menjadi global dengan adanya praktik turisme.

"Instead of checking in to hotel in Tehran, we decide to stay in outskrits of the city. We found a lovely house decorated with Persian style which the owner rent to tourist. It's a good decision with the enjoyable retreat and its owner very welcoming and hospitable" (majalah maskapai penerbangan Travel 3Sixty rubrik Travel log edisi bulan Juni 2017: 106).
Sama halnya dengan konsep budaya, objek wisata yang memiliki nilainilai lokal seperti sejarah lokal, bangunan bersejarah, bahkan tempat-tempat ibadah kemudian menjadi global dengan berkembangnya turisme. Dalam proses perubahan dari tradisional ke global ini, tentunya, terdapat pengaruh-pengaruh dari luar seperti industrialisasi, urbanisasi, perbedaan budaya dan sebagainya yang mencerminkan nilai kebarat-baratan (Featherstone, 1993: 170).

Bukan hanya aspek budaya, aspek pemandangan pun menjadi global dengan adanya media. Informasi dalam artikel maupun iklan akan sebuah tempat saat ini menggambarkan ruang yang sempurna. Konsep ruang tersebut ditampilkan dengan sudut pandang global dari unsur kelokalan yang diubah menjadi global.

Konsep global lainnya dalam mendapatkan pengalaman liburan yang sempurna adalah dengan menikmati sebuah ruang secara keseluruhan. Dalam artikel bulan Mei 2015, ditulis sebagai berikut.

"It was hot, sunny day on the exquisite white sand beach. We had cold drinks and read books while getting tanned. It was just lovely." (majalah maskapai penerbangan Travel 3Sixty rubrik Travel Log edisi bulan Mei 2015: 124)

Konsep global juga terlihat dari bagaimana visual dalam artikel mempresentasikan sebuah ruang. Dalam menampilkan visual ruang, pemilihan warna sangat diperhatikan sehingga dapat memberikan daya tarik dan ekspektasi yang tinggi bagi pembaca atau konsumennya. Pemandangan pegunungan yang berjajar berwarna hijau atau putih tertutup salju, atau penggambaran pantai yang memiliki pasir yang putih dengan air 
yang jernih adalah beberapa contoh. Penggambaran global pada ruang budaya, misalnya, sebuah ruang yang memiliki berbagai macam kemudahan dalam mengaksesnya atau penampilan jalan dan bangunan yang tertata bersih dan rapih.
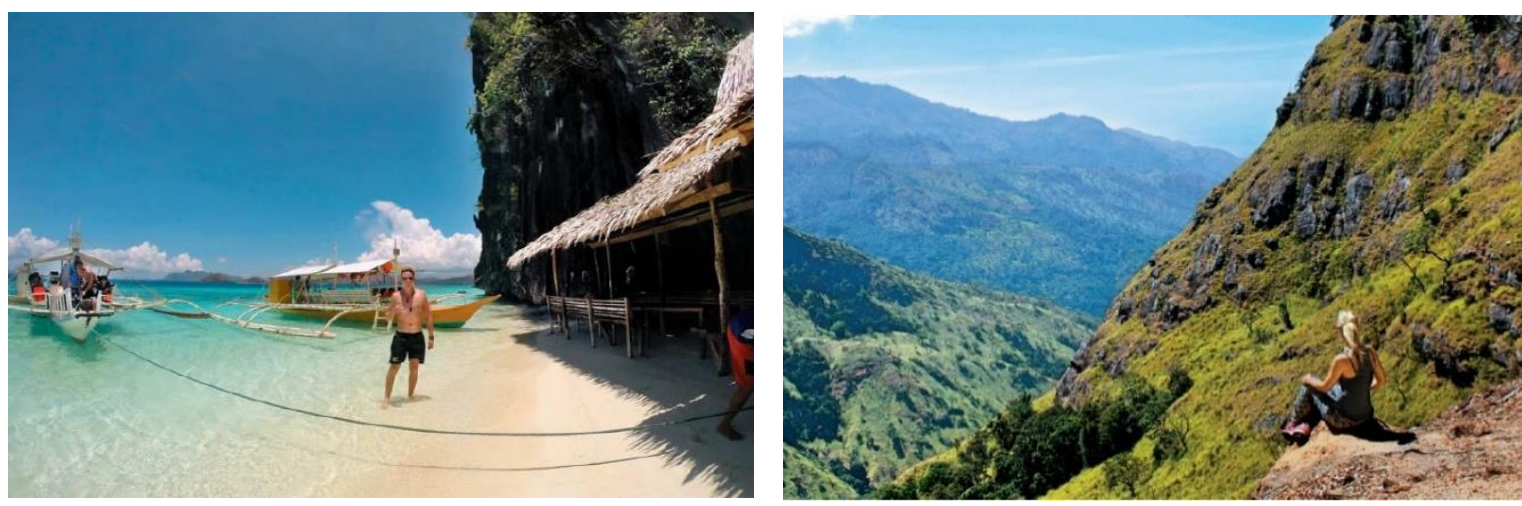

Gambar 1 Penampilan Ruang Pemandangan Alam dalam Konstruk Global
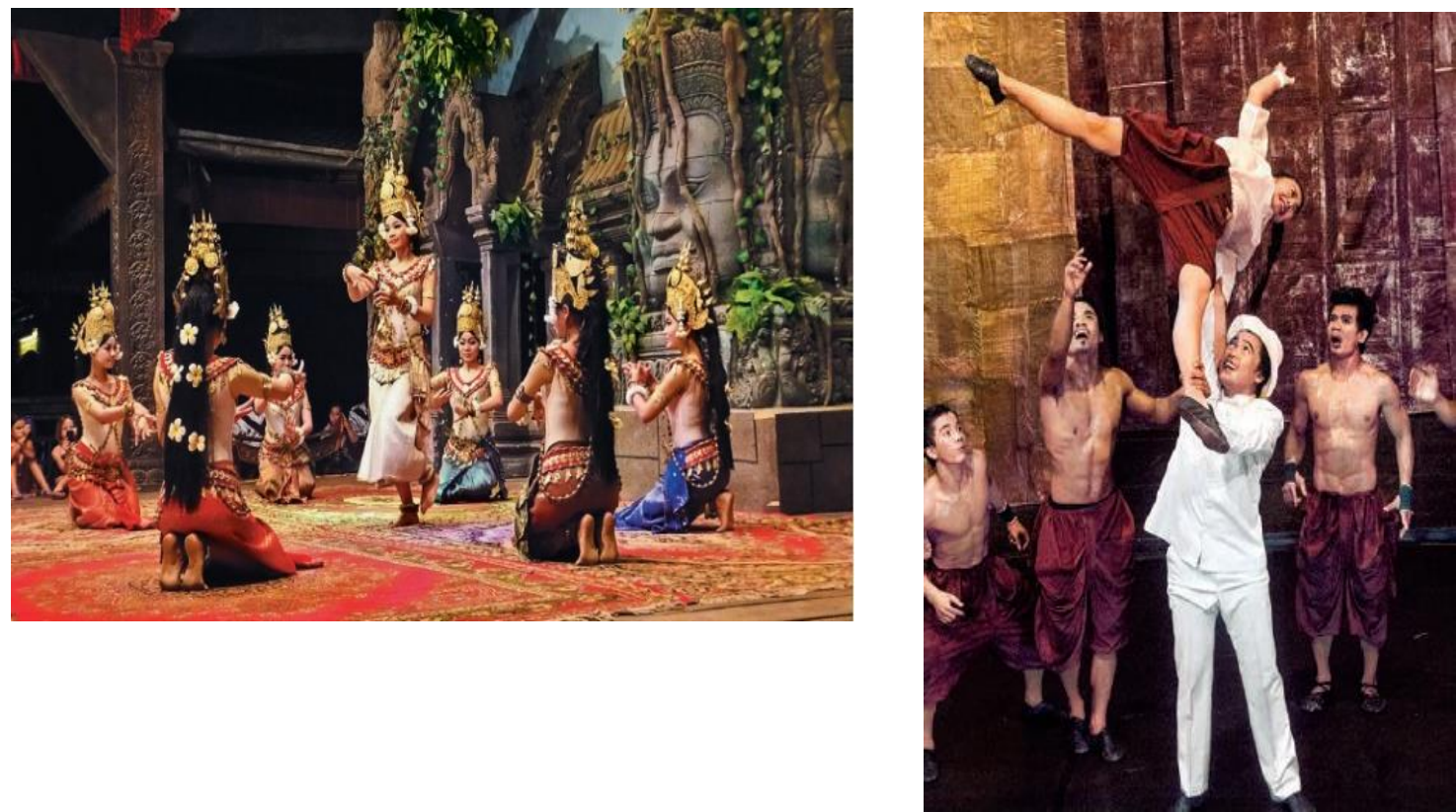

Gambar 2 Penampilan Atraksi Lokal Menjadi Global dengan Tujuan Pariwisata

Namun, penggambaran dalam artikel atau media pariwisata termasuk juga majalah maskapai penerbangan menjadi klise dimana mereka hanya memberikan hal-hal positif demi mengkonstruksikan ruang agar menghasilkan liburan yang sesuai dengan apa yang diharapkan. Penampilan tersebut memberikan penggambaran mengenai sebuah aspek pemandangan yang belum tersentuh, dan berbeda dari tempat asal calon turis (Maci, 2012: 202) sehingga menghasilkan sebuah stereotip akan sebuah tempat sendiri. 


\section{Kesimpulan}

Penelitian ini dilakukan untuk meneliti konstruksi ruang dan pengalaman keruangan atas Asia dalam majalah maskapai penerbangan AirAsia, Travel 3Sixty. Perkembangan media dan komunikasi mengkonstruk sebuah tempat, tak terkecuali media dan komunikasi yang mempunyai fungsi pariwisata. Dengan adanya konstruk pada sebuah tempat, wisatawan dapat memilih dan mengevaluasi tempat-tempat yang dikunjungi.

Asia sendiri dikonstruksikan menjadi tempat yang dapat menyuguhkan berbagai macam pengalaman mulai dari ruang hingga pengalaman atas ruang. Dalam mengalami ruang di Asia, banyak wisatawan berkunjung ke tempat-tempat budaya dan pemandangan. Hal ini karena kebanyakan wisatawan melakukan perjalanan dengan tujuan untuk relaksasi dan menghibur diri serta mendapatkan pengalaman dan pengetahuan yang baru. Selain itu, terdapat juga wisatawan yang mengunjungi tempat-tempat layanan dan rekreasi.

Majalah maskapai penerbangan sebagai media yang memiliki genre global memediasi tatapan turis terhadap Asia. Asia dikonstruksikan memiliki otensitas (authentic) dengan beragam budaya, tempat budaya di Asia sendiri juga di konstruk memiliki keramahan terutama pada penampilan masyarakat lokal yang selalu ramah terhadap wisatawan. Dalam menampilkan Asia yang otentik, tempattempat yang sebenarnya bukan ruang wisata pun dikonstruksikan sebagai destinasi wisata, misalnya, tempat ibadah.

Asia juga dikonstruksikan sebagai tempat yang memiliki keaslian yang baru. Maksudnya, Asia dapat memberikan pengalaman yang baru serta berbeda dari yang biasa dijalani dengan mengunjungi tempat-tempat tradisional.

Perkembangan media dan pariwisata global juga berpengaruh pada konstruk Asia sebagai objek global dimana majalah maskapai penerbangan menampilkan aspek kelokalan dan otentik menjadi aspek yang dapat dikonsumsi masyarakat global. Selain itu, penampilan unsur lokal yang dikontruk menjadi global juga dapat berpengaruh pada konsumsi masyarakat global pada kelokalan di Asia.

Selain ruang, pengambilan gambar dan konsep gambar atau visual juga menjadi global dengan adanya media. Pengambilan serta penampilan gambar dalam media global dapat menjadi motivasi wisatawan untuk mendapatkan pengalaman yang ideal. Pengalaman yang ideal sendiri merupakan konstruk dari konsumsi global yang meneritakan sebuah pengalaman dengan identitasnya masingmasing.

Globalisasi akibat media juga tidak hanya penampilan visual dalam media namun juga mempengaruhi tatapan wisatawan dalam mengambil gambar di sebuah ruang wisata. Misalnya, dalam pemilihan fokus gambat, letak objek dalam gambar, hingga pemilihan warna dalam pengambilan gambar. 


\section{DAFTAR PUSTAKA}

Adiputra, Wisnu Martha. (2008). Analisis Isi. dalam Metode Riset Komunikasi: Panduan Untuk Melaksanakan Penelitian Komunikasi, Ed. Pitra Narendra. Hal. 103-116.

Cohen, Erik. A Phenomenology of Tourist Experience. Sociology, (1979). SAGE Social Science Cellections.

Daye, Marcella. (2005). "Mediating Tourism: An Analysis of the Caribbean Holiday Experience in the UK National Press." dalam The Media and the Tourist Imagination: Converging Cultures, eds. David Crouch, Rhona Jackson, dan Felix Thompson. Hal. 14-26. New York: Routledge.

Dhona, Holy R. 2018. Mencipta Ruang Global Indonesia Di Majalah Maskapai Penerbangan Garuda Indonesia Colours. IPTEK-KOM, Vol. 20 No. 1, Juni 2018: 43-60

Dilley, Robert S. "Tourist Brochures and Tourist Images." The Canadian geographer / Le Géographe Canadien 20, No. 1. (1986). hal. 5965.

Eriyanto. (2009). Analisis wacana. Yogyakarta: LKiS Yogyakarta.

Featherstone, Mike. (1993). "Chapter 10: Global and Local Cultures." dalam Mapping the Futures Local Cultures, Global Change, eds. Jon Bird, Barry Curtis, Tim Putnam, George Robertson, Lisa Tickner. Hal. 169-187.
Lisle, Debbie. (2006). "The Global Politics of Contemporary Travel Writing." Cambridge University Press: British Library.

Maci, Stefania Maria. "Glocal Features of In-Flight Magazines: When Local Becomes Global. An Explorative Study." Confine mobile: lingua $e$ cultura nel discorso del turismo, (Febuari, 2012), Hal 196-218.

Phillips, M. Kim. (2014). Before Orientalism. Asian Peoples and Cultures in European Travel Writing, 1245-1510. Pennsylvania: University Of Pennsylvania Press.

Thompson, Carl (ed). (2016). The Routledge Companion to Travel Writing. Abingdon: Taylor and Francis Group.

Thurlow, Crispin, dan Adam Jaworski. "Communicating a Global Reach: Inflight Magazines as a Globalizing Genre in Tourism." Journal of Sociolinguistic 7/4 (2003), hal. 579-606.

Urry, John. (2005). The Tourist Gaze. London: SAGE Publications Ltd.

Ye, Helen, dan Iis P. Tussyadiah. "Destination Visual Image and Expectation of Experiences." Journal of Travel \& Tourism Marketing, Vol. 28 (2011), hal. 129144. 